\title{
15-0063 \\ Performance Ranking of Arterial Corridors \\ Using Travel Time and Travel Time Reliability Metrics
}

Christopher M. Day', Stephen M. Remias', Howell Li', Michelle M. Mekker', Margaret L. McNamara', Edward D. Cox², and Darcy M. Bullock

\section{ABSTRACT}

Performance measures are important for managing transportation systems and demonstrating accountability. Probe vehicle data has emerged as a means of gathering vast amounts of information about highway networks. This paper presents a scalable methodology for analyzing arterial travel times, taking into account both the central endency of the travel time and its reliability. A pilot analysis is carried out for 28 arterials with a total of 341 signalized intersections across the state of Indiana. Starting from agiviual minute-by-minute speed records, the data are converted into travel times and periods, reflecting differest cohorts that correspond to typical traftic signal time-of-day

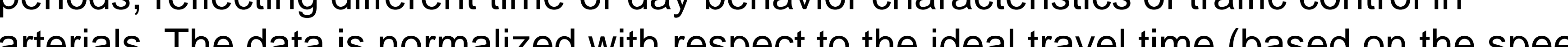
limits on eac route) to account for individual route lengths and speeds. Das on the speed or all Wednesdays from January through July 2014 to investigate arterial characteristics. The data shows that a greater density of traffic signals on a route loosely corresponds to higher average travel times and less reliability. A composite index incorporating both the average values and reliability characteristics of travel time is developed, and used to rank the arterials according to their performance.

\section{SURVEY OF ARTERIALS}

Arterial Routes Selected for Study

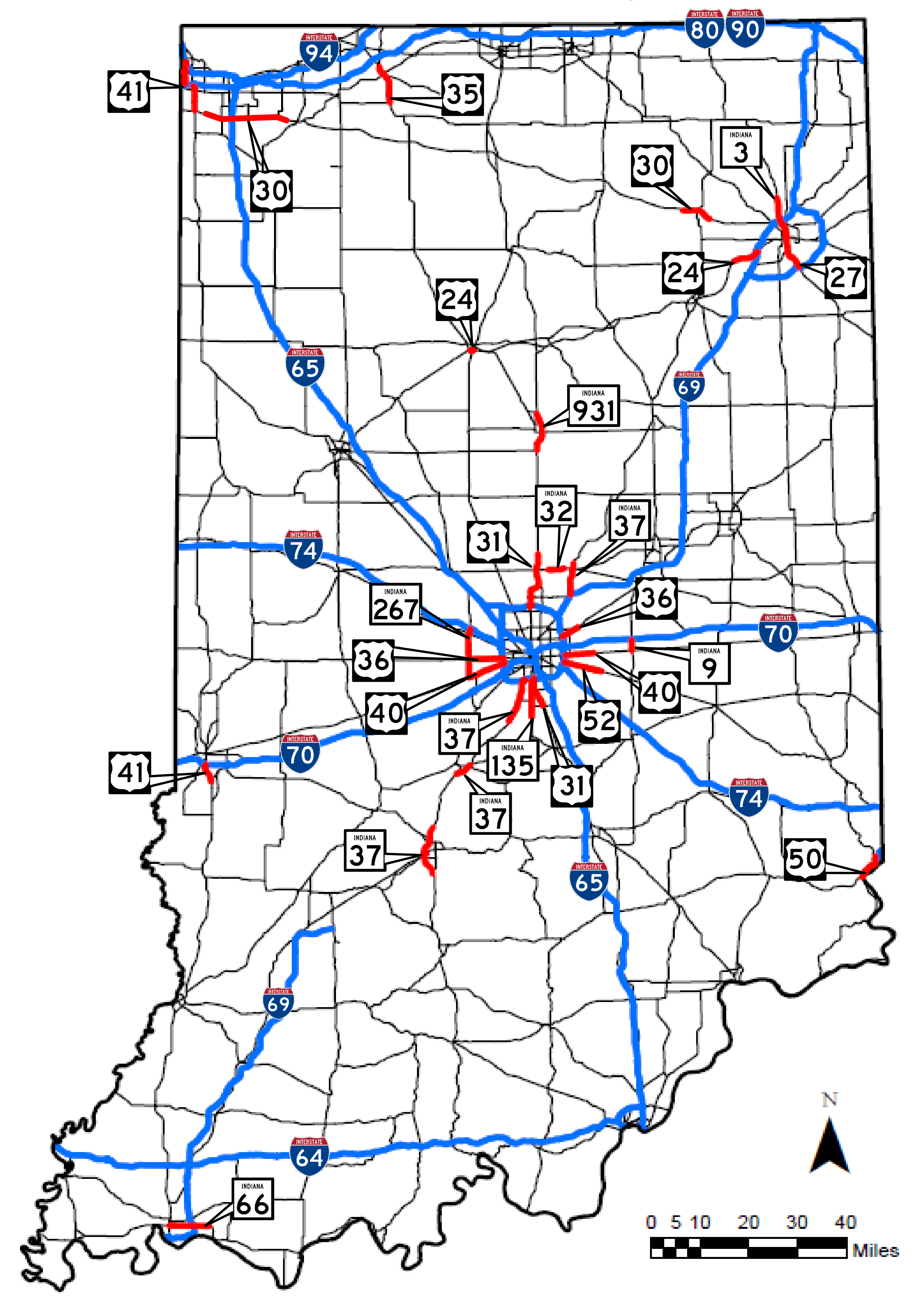

\section{DATA QUALITY}

Freeway versus Arterial Data Coverage
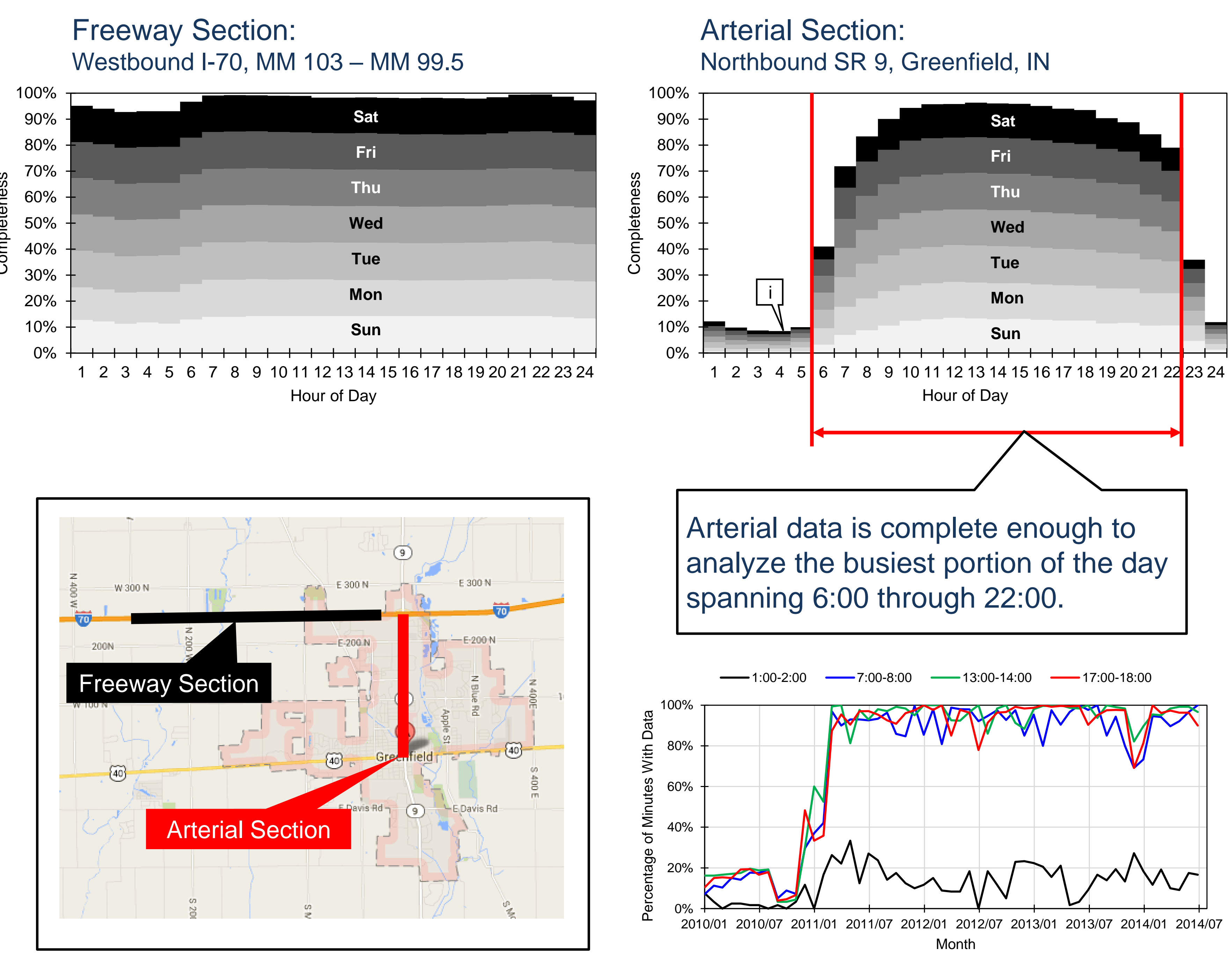

Arterial data is complete enough to analyze the busiest portion of the day
spanning 6:00 through 22:00.

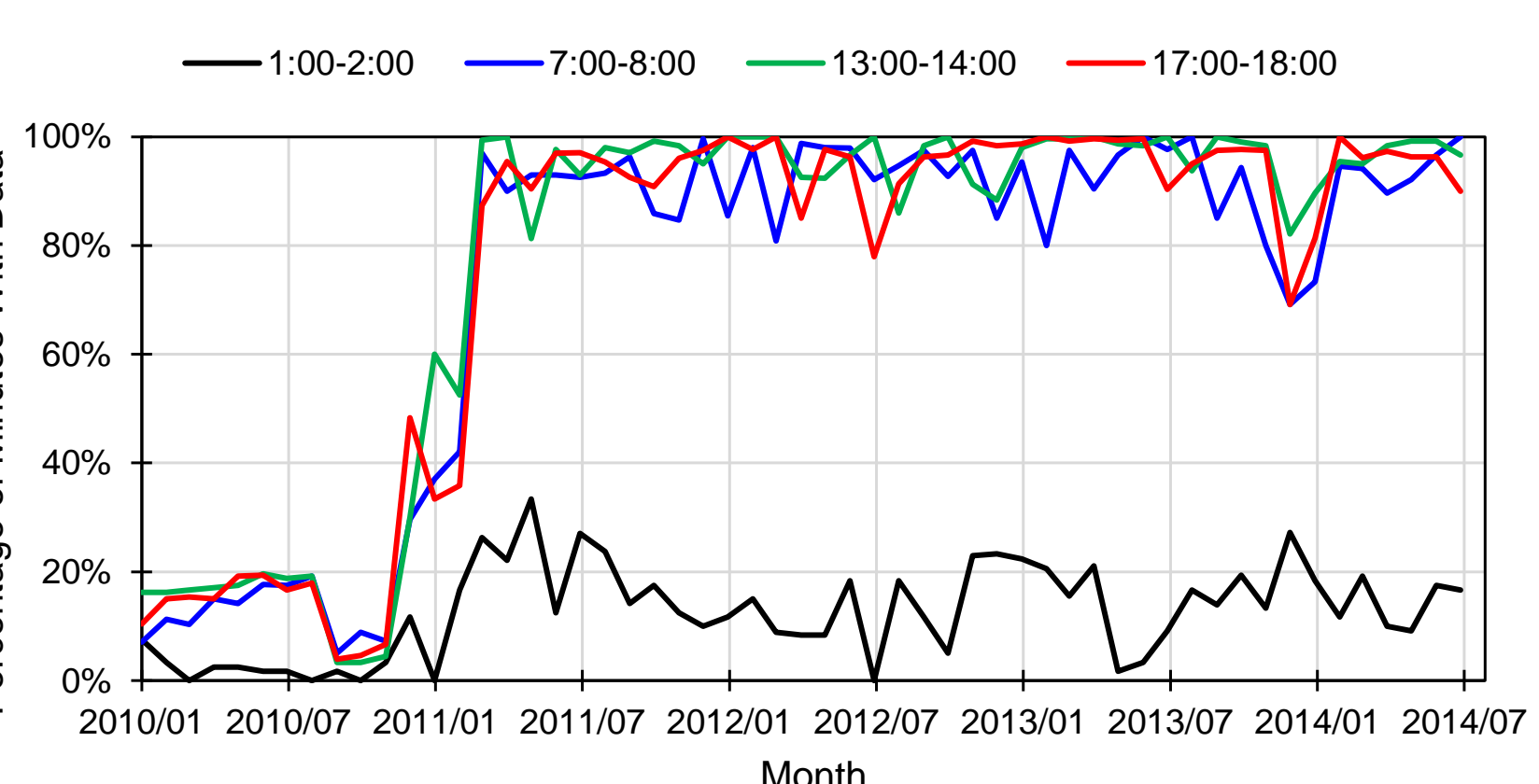

\section{PERFORMANCE MEASURE}

Data must be normalized because routes are of different length.

Travel Rate method expresses travel time as amount of time per mile.

Normalization To Ideal Travel Time expresses travel time as percentage of the idea

This analysis uses speed limit travel time as surrogate for ideal travel time.

This analysis uses normalization to speed limit travel time in order to compare muliple roadways with different travel speed expectations.

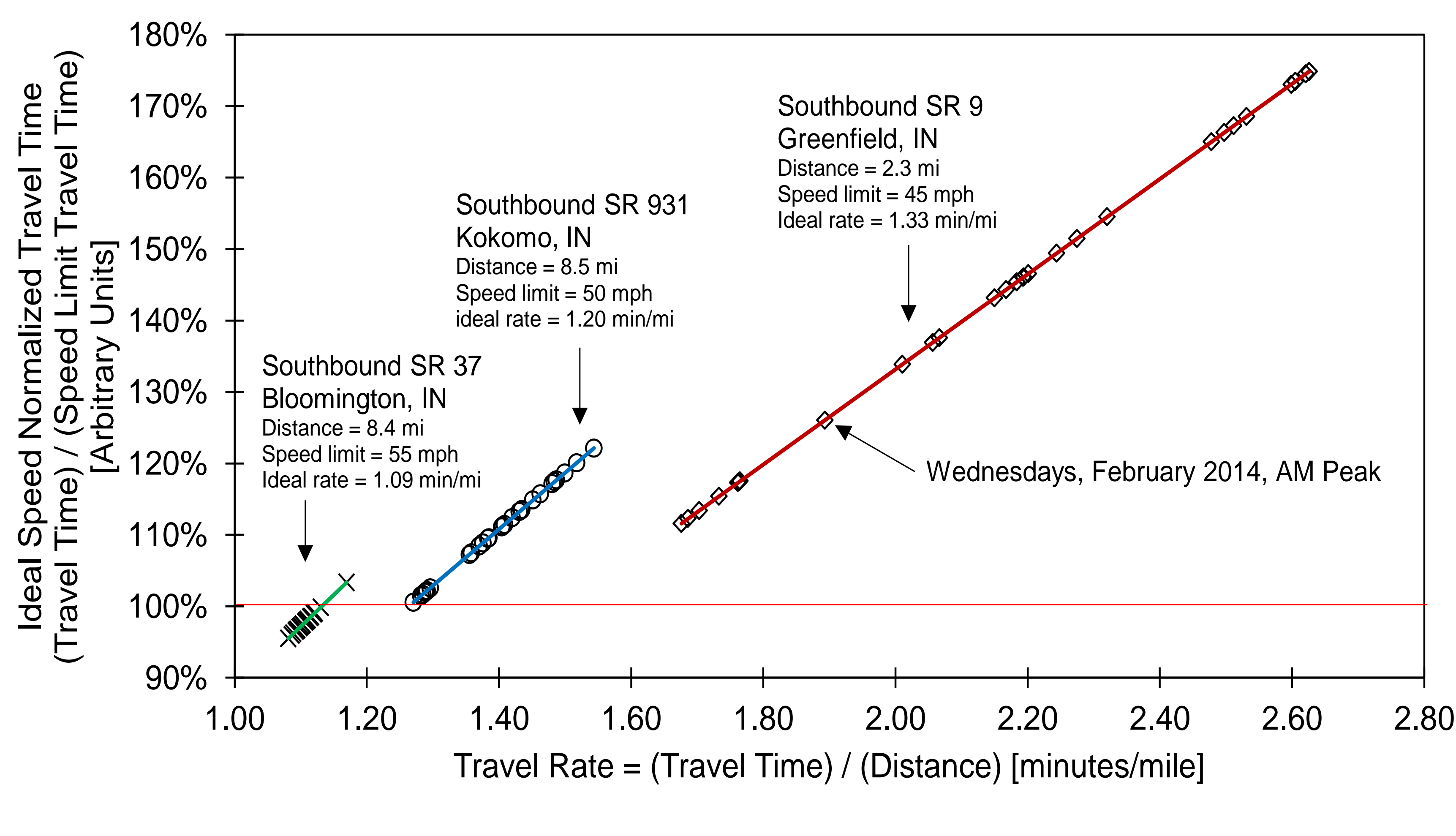

\section{RANKING METHODOLOGY}

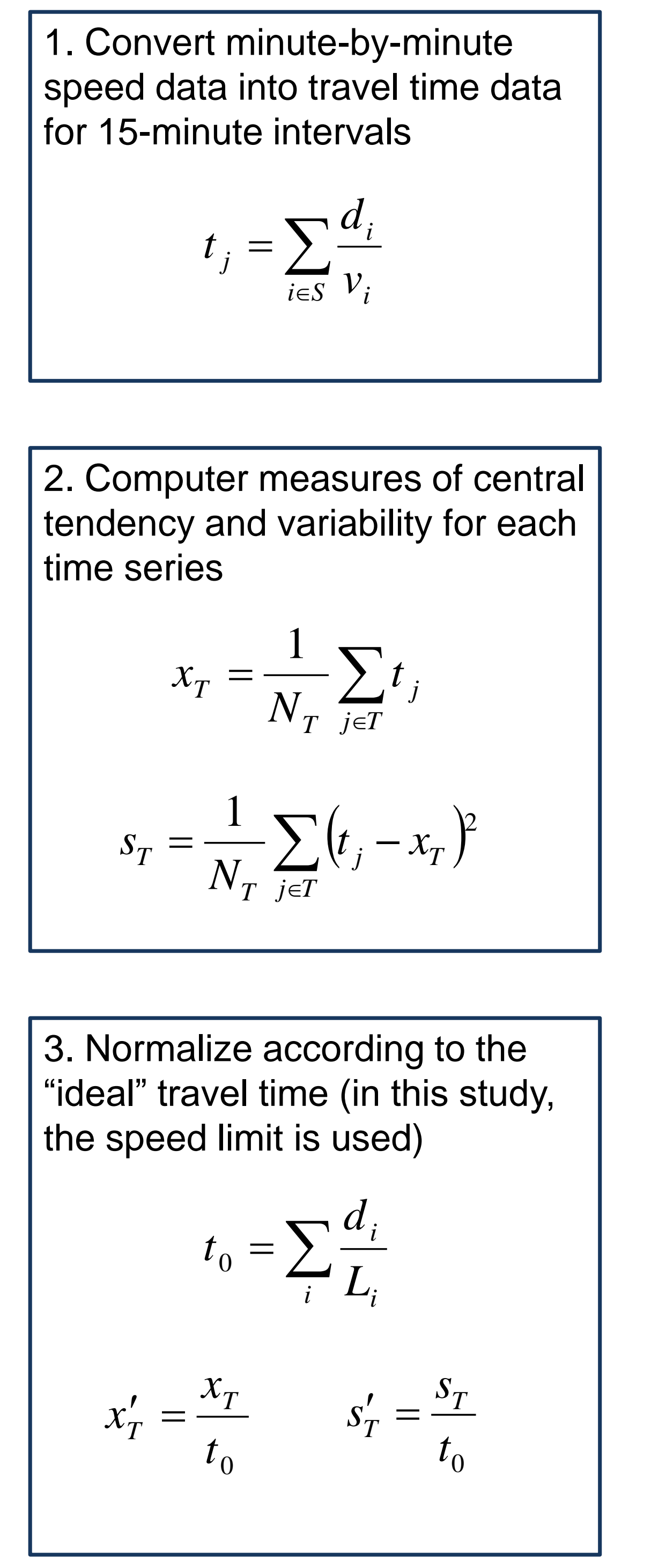

Normalization of Central Tendency

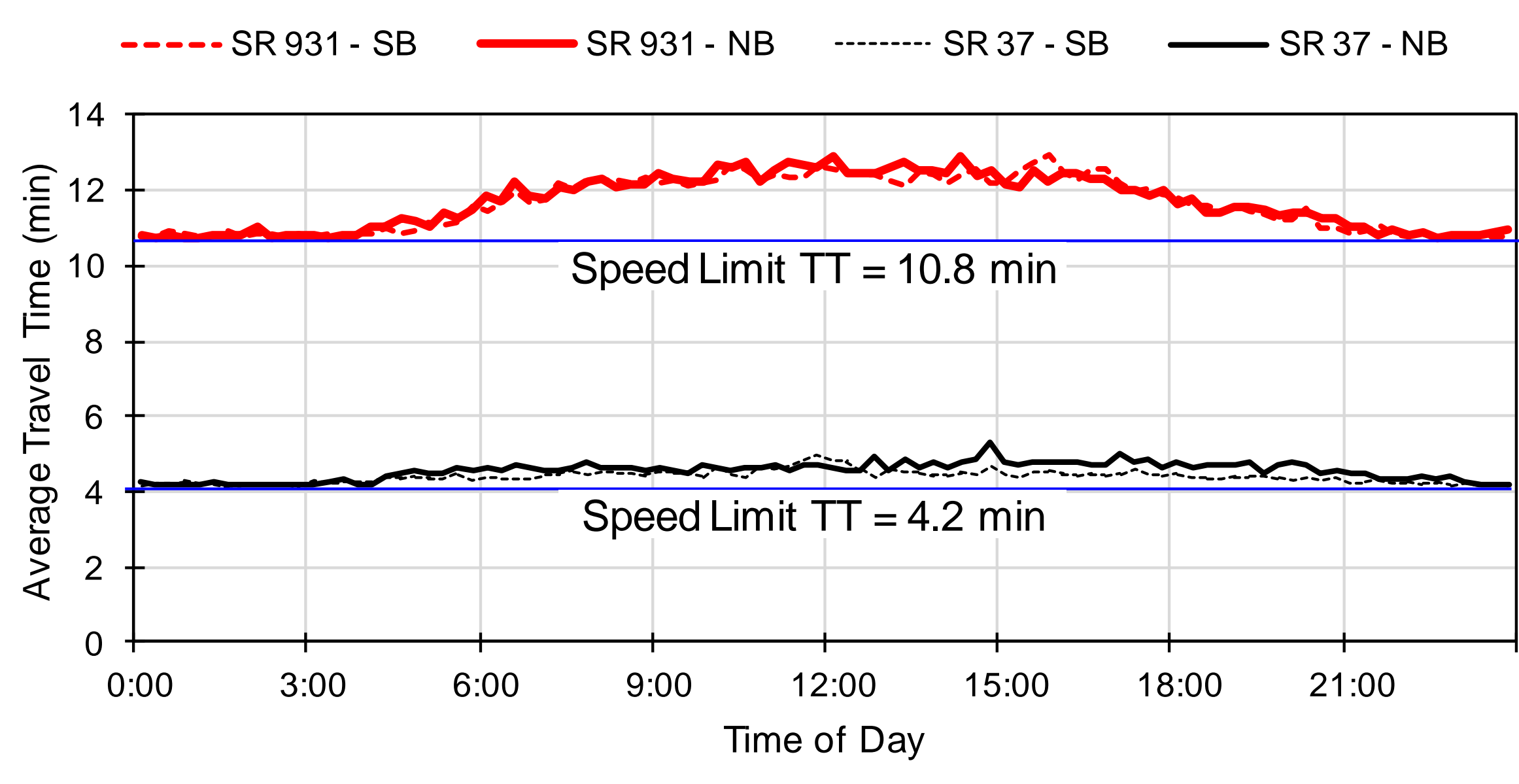

After

Before

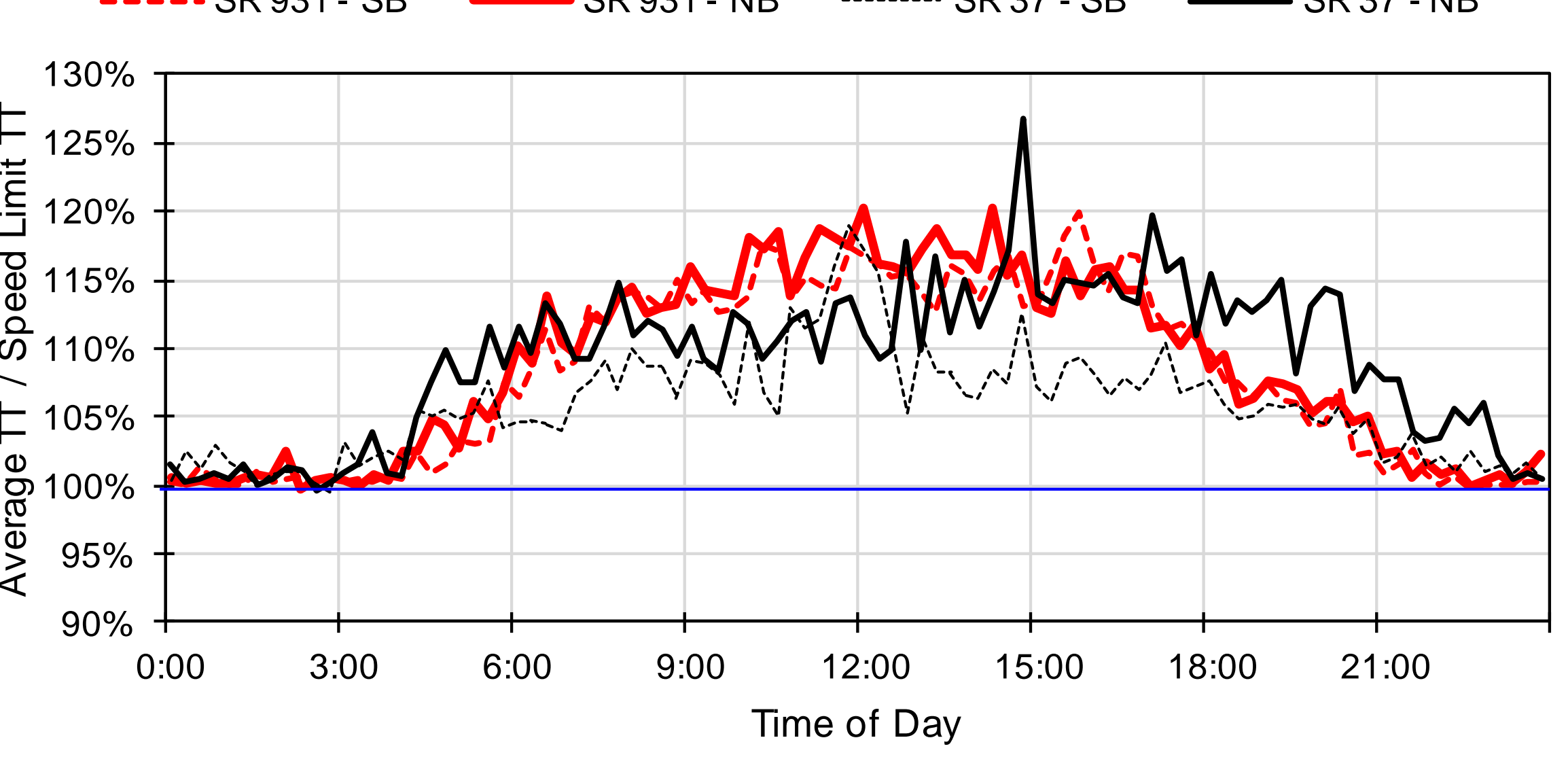

Normalization of Variability (Reliability)
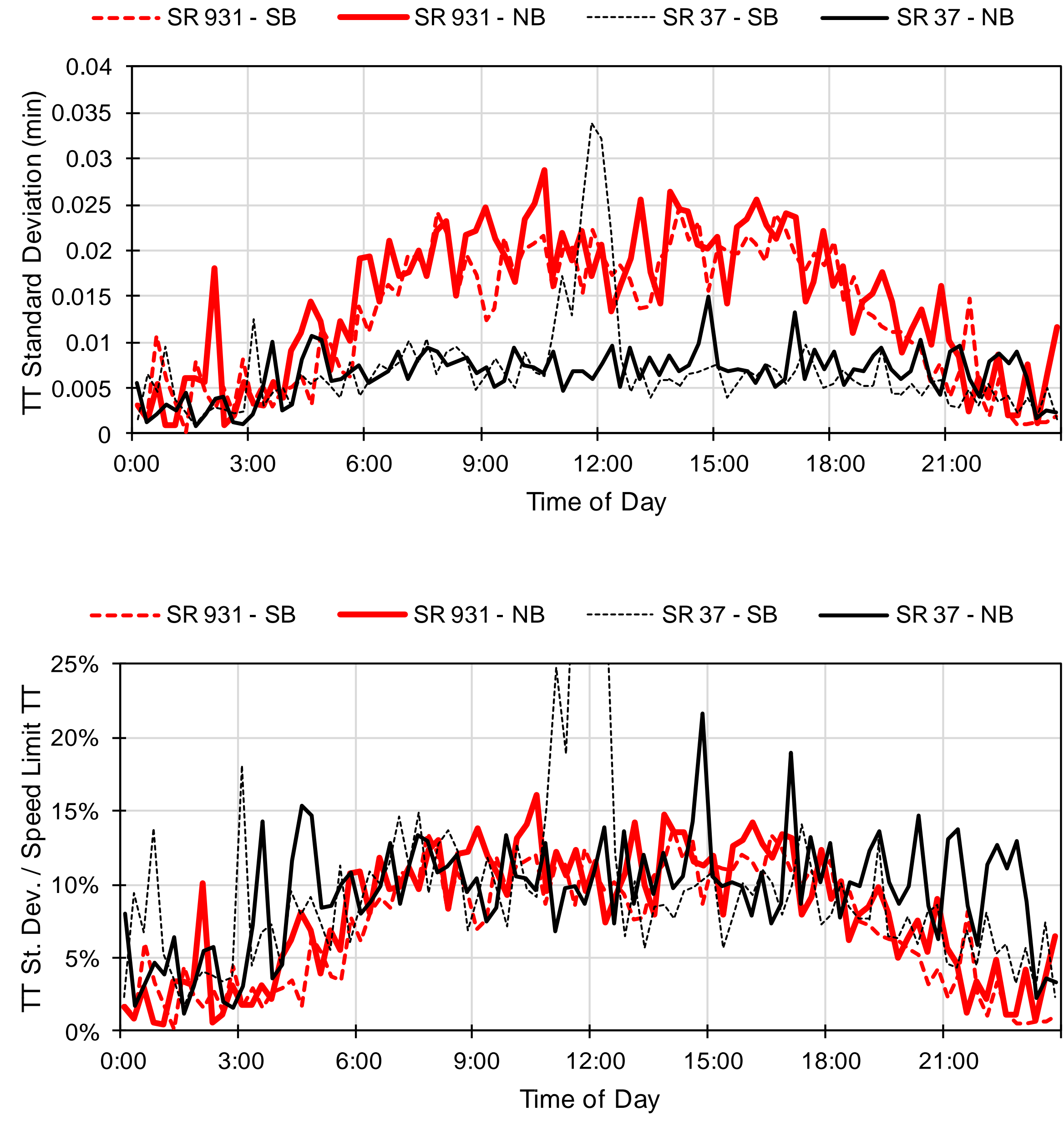


\section{5-0063}

\section{Performance Ranking of Arterial Corridors}

Using Travel Time and Travel Time Reliability Metrics

\section{ARTERIAL RANKING BY TIME OF DAY}

AM Peak (Top 10)

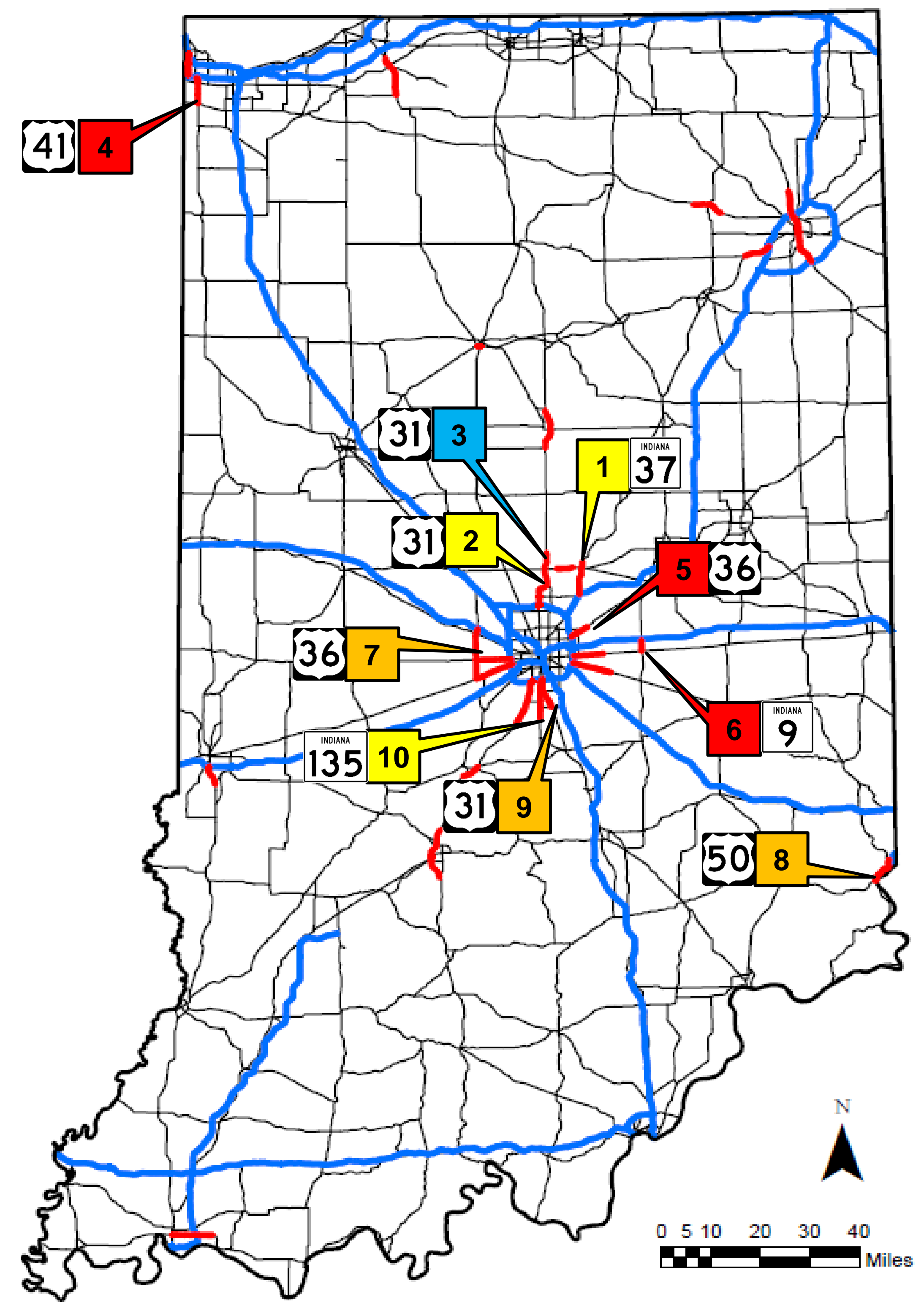

Midday (Top 10)

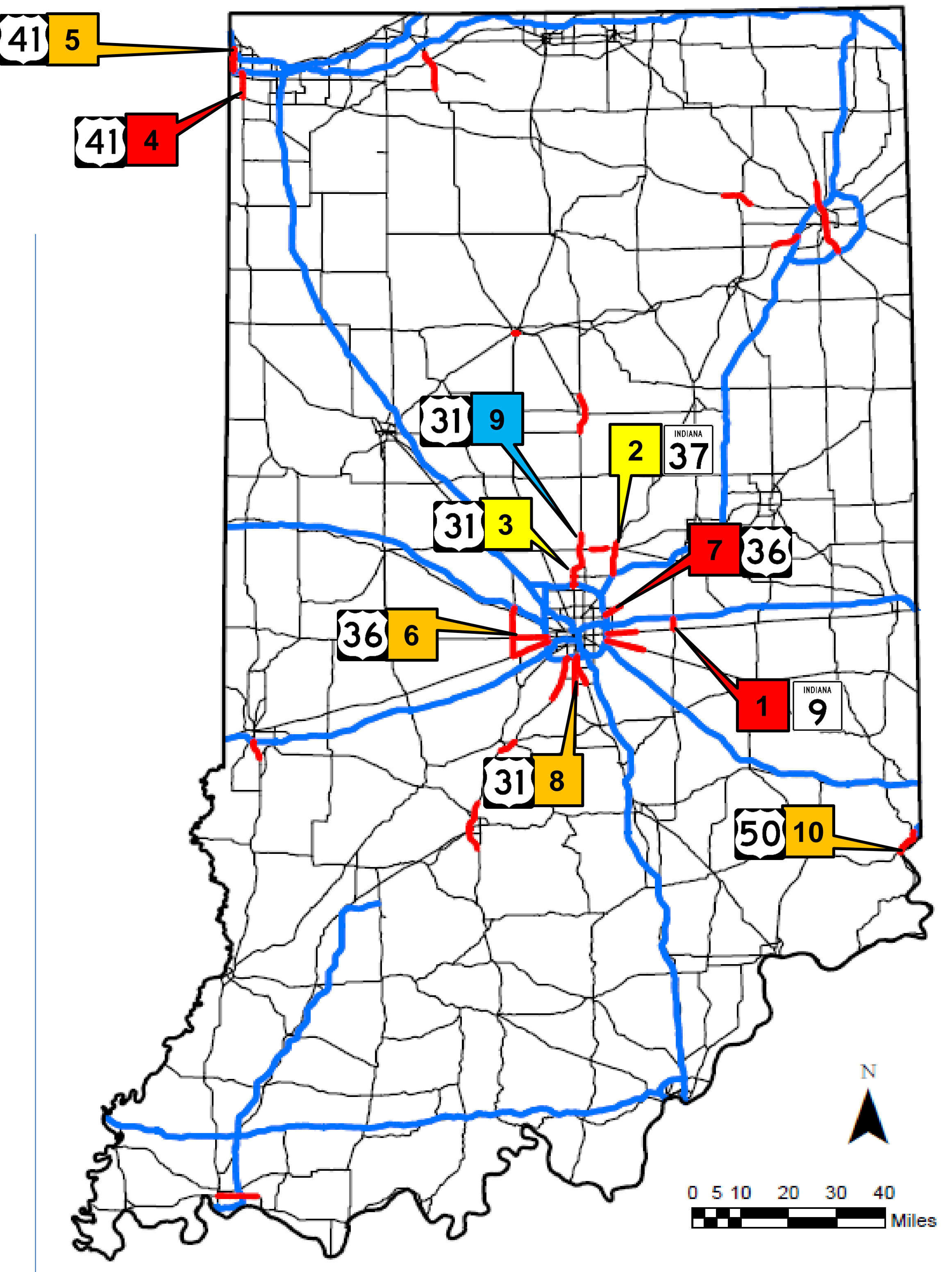

PM Peak (Top 10)

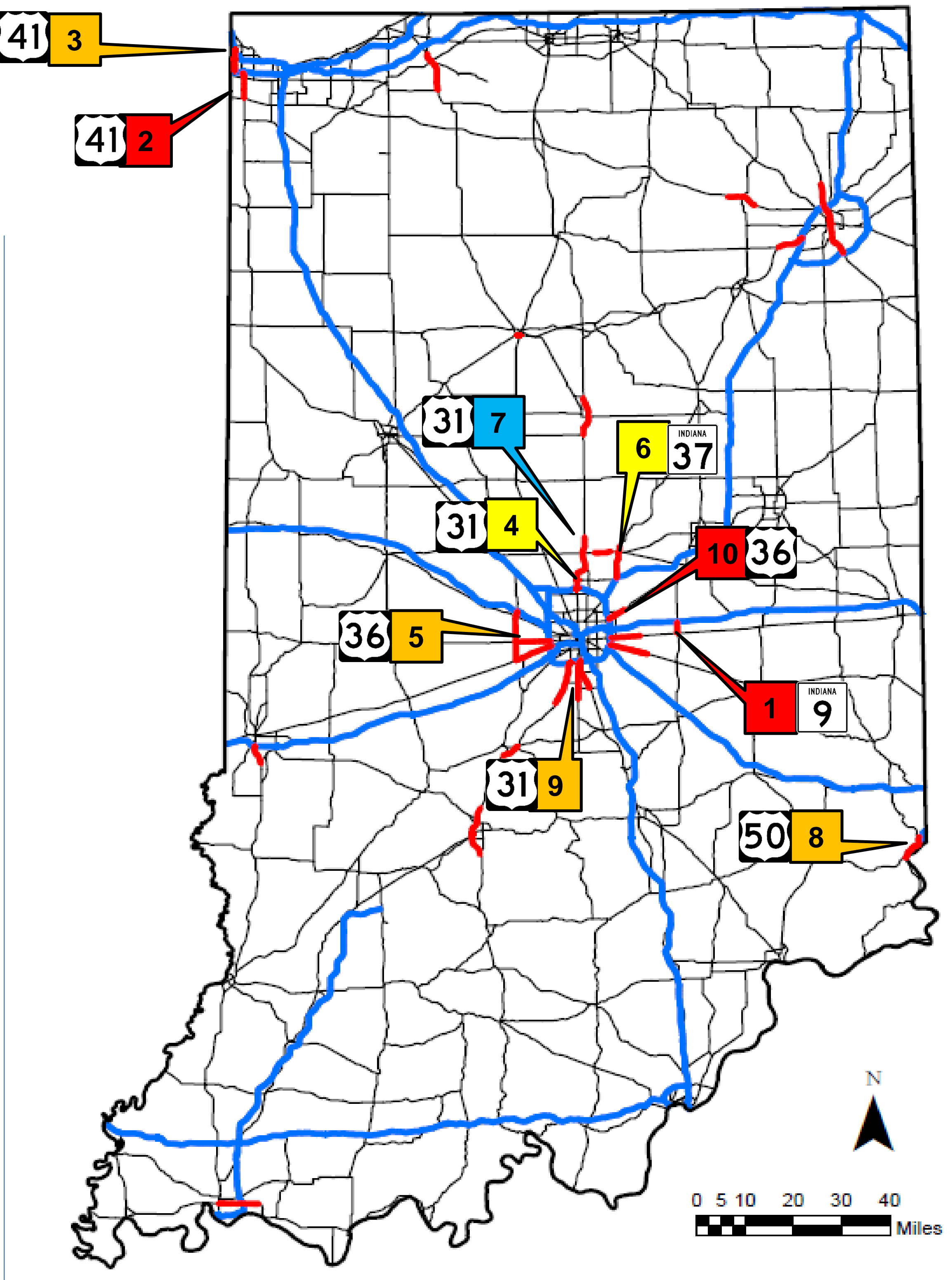

\section{OVERALL RANKING}
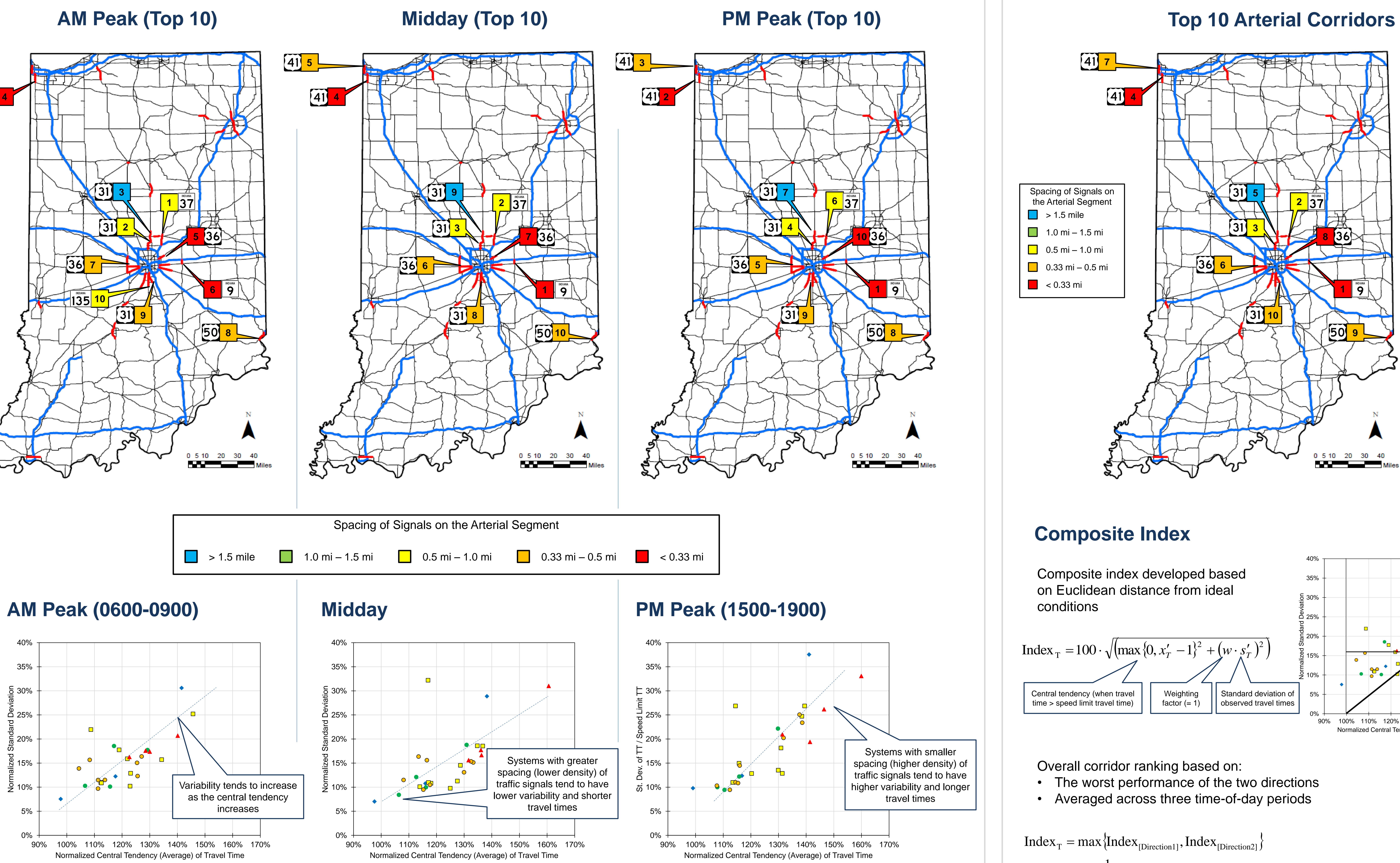

\section{Composite Index}

Composite index developed based on Euclidean distance from ideal conditions

\begin{tabular}{llllllllll}
\hline$U$ & $N$ & $I$ & $V$ & $E$ & $R$ & $S$ & $I$ & $T$ & $Y$
\end{tabular}

Index $_{\mathrm{T}}=100 \cdot \sqrt{\left(\max \left\{0, x_{T}^{\prime}-1\right\}^{2}+\left(w \cdot s_{T}^{\prime}\right)^{2}\right)}$

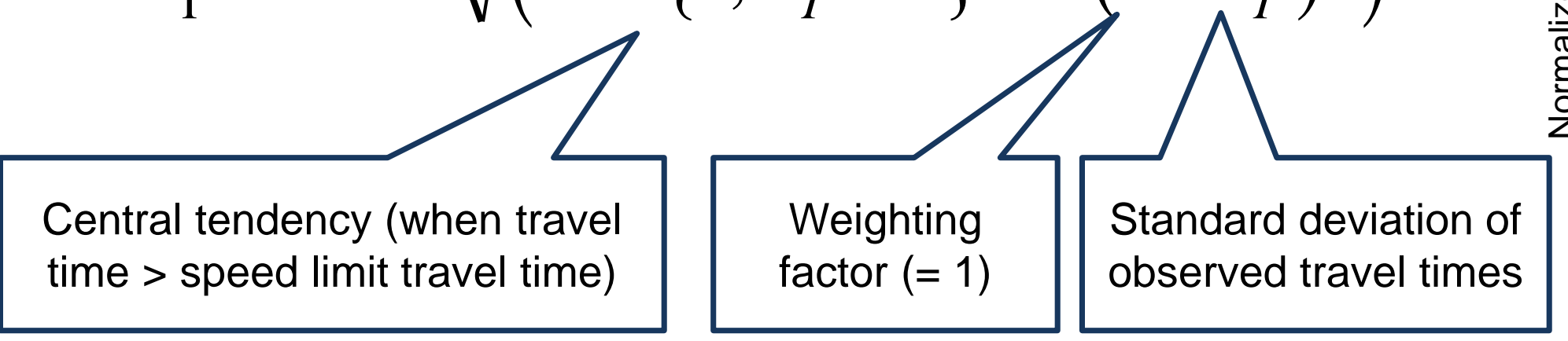

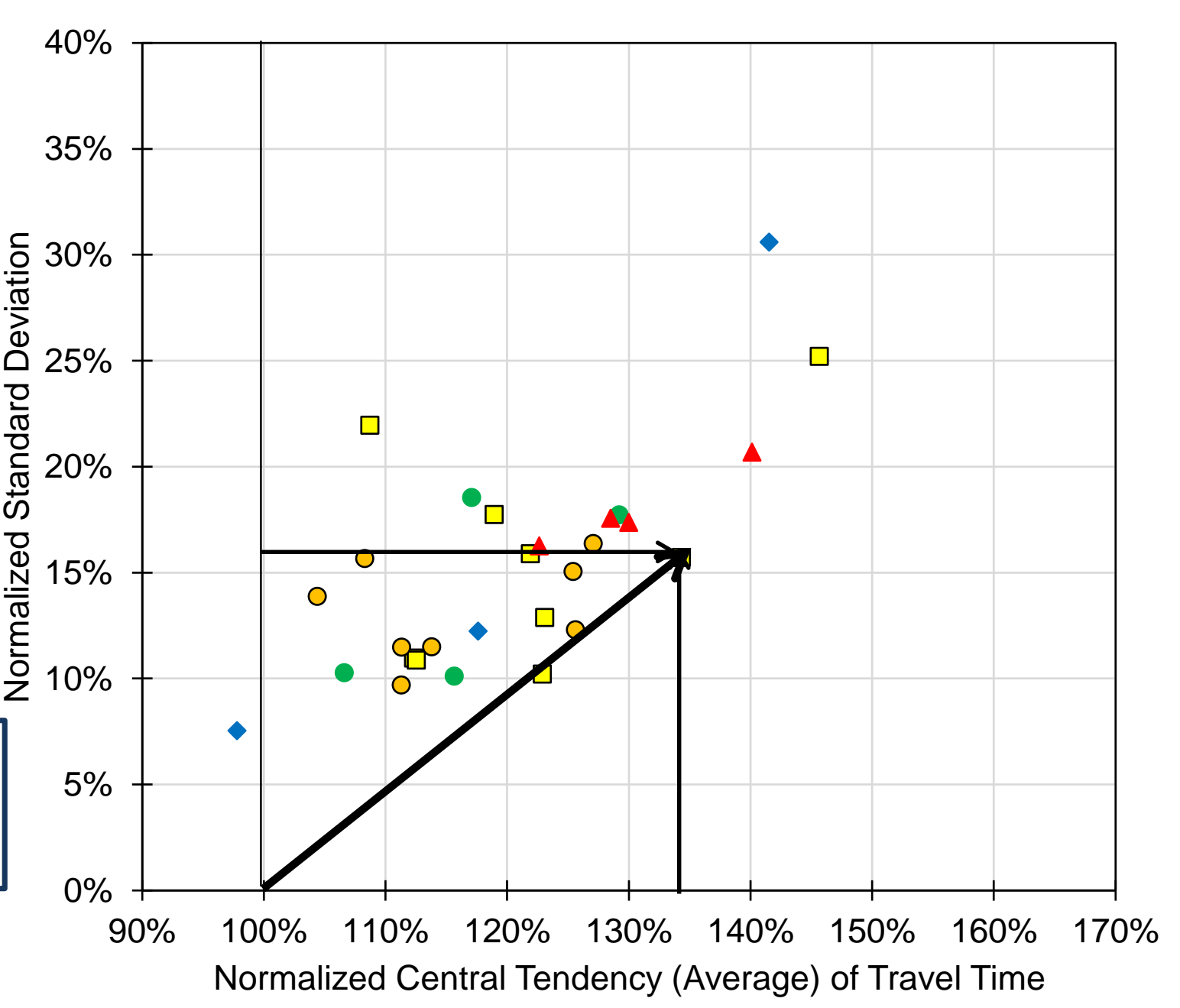

Overall corridor ranking based on:

The worst performance of the two directions

Averaged across three time-of-day periods

$\operatorname{Index}_{\mathrm{T}}=\max \left\{\operatorname{Index}_{[\text {Direction] }]}, \operatorname{Index}_{[\text {Direction2] }}\right\}$

Index $_{\text {corridor }}=\frac{1}{N} \sum_{T}$ Index $_{T}$ 